\title{
Microneedle for transdermal drug delivery: current trends and fabrication
}

\author{
Jae Hwan Jung ${ }^{1}$ Sung Giu Jin ${ }^{1,2}$
}

Received: 30 April 2020 / Accepted: 13 January 2021 / Published online: 4 March 2021

(c) The Korean Society of Pharmaceutical Sciences and Technology 2021

\begin{abstract}
Background Transdermal delivery has the advantage of bypassing the first-pass effect and allowing sustained release of the drug. However, the drug delivery is limited owing to the barrier created by the stratum corneum. Microneedles are a transdermal drug delivery system that is painless, less invasive, and easy to self-administer, with a high drug bioavailability. Area covered The dose, delivery rate, and efficacy of the drugs can be controlled by the microneedle design and drug formulations. This review introduces the types of microneedles and their design, materials used for fabrication, and manufacturing methods. Additionally, recent biological applications and clinical trials are introduced.

Expert opinion With advancements made in formulation technologies, the drug-loading capability of microneedles can be improved. 3D printing and digital technology contribute to the improvement of microneedle fabrication technology. However, regulations regarding the manufacture of microneedle products should be established as soon as possible to promote commercialization.
\end{abstract}

Keywords Drug delivery $\cdot$ Microneedles $\cdot$ Transdermal $\cdot$ Fabrication techniques $\cdot$ Clinical trial

\section{Introduction}

The efficacy of pharmaceuticals depends on not only the properties of the active drug component but also the mechanism underlying its delivery to the body (Tibbitt et al. 2016). Therefore, it is critical to investigate an optimal method for drug delivery in accordance with the characteristics of the drug. Oral administration is a simple and convenient drug delivery method because the patient can self-administer the drug; however, its application to biopharmaceuticals is challenging (Homayun et al. 2019). Injections result in high bioavailability and rapid onset of drug action. However, expertise is required for administration and patient compliance is low (Prausnitz 2017). Therefore, the ideal drug delivery method should be as simple as oral administration

Sung Giu Jin

sklover777@dankook.ac.kr

1 Department of Pharmaceutical Engineering, Dankook University, 119 Dandae-ro, Dongnam-gu, Cheonan 31116, Republic of Korea

2 Center for Bio-Medical Engineering Core Facility, Dankook University, 119 Dandae-ro, Dongnam-gu, Cheonan 31116, Republic of Korea and should exhibit high bioavailability as with injection. Transdermal delivery has the advantage of bypassing the first-pass effect and allowing sustained release of the drug. However, drug delivery is difficult due to the barrier created by the stratum corneum (Dharadhar et al. 2019). Microneedles are a platform for transdermal drug delivery; it is easy to self-administer, and it exhibits a high drug bioavailability (Prausnitz 2017). In addition, it is a painless and less invasive method that enables the drug to directly pass through the stratum corneum, which is the largest barrier of the skin (Ye et al. 2018; Kim et al. 2012; Ma and Wu 2017; Prausnitz et al. 2008). The advantages and disadvantages of microneedles as a transdermal delivery system are summarized in Table 1. The dose, delivery rate, and efficacy of the drugs can be controlled by the microneedle design and drug formulation. Till date, studies have been conducted on microneedles formulated using various manufacturing methods and materials for delivering drugs and cosmetics (Donnelly et al. 2010; Ma et al. 2017). The efficacy and safety of microneedles have been demonstrated through animal experiments and clinical trials (Bhatnagar et al. 2017; Queiroz et al. 2020). In this review, we summarize the types of microneedles required for microneedle design, materials used for fabrication, and manufacturing methods. 
Table 1 Advantages and disadvantages of microneedles as a transdermal delivery tool

1. Advantages

Improve drug delivery (1) Drugs are delivered directly into the body through the stratum corneum

(2) Onset of drug action is rapid (since there are capillary bed and associated lymphatic vessels in the superficial dermis)

(3) Accurate drug dose is delivered by controlling microneedle formulations

(4) Microneedles avoid the first-pass metabolism

(5) Microneedles enable high drug bioavailability

(6) It is effective for vaccine delivery because of the abundance of immune cells in the dermis

Improve safety and patient compliance

(1) Microneedles are painless and safe because of their small length and size

(2) The need for expertise is reduced for the patch application

(3) Microneedle patches reduce or eliminate biohazardous sharps waste

Improve manufacturing process and

(1) The optimized solid-state formulation of the microneedle does not need the cold-chain system cost-saving

(2) Microneedle patches, which encompass the functionality of the drug, needle, and syringe, reduce the overall size of the drug package

(3) Microneedle patches save cost in terms of dose sparing, manufacturing, and logistics

2. Disadvantages

(1) Drug dose is limited due to the small size of the microneedle

(2) Temporary inflammation and allergy can be caused

(3) Sophisticated technologies are needed for manufacturing a microneedle patch with reproducibility

(4) Microneedle patches need a storage container for holding the microneedle patches hygienically without damage during distribution from the manufacturers to the patients

(5) When the solid microneedles are applied, some part of the microneedles can be broken or left in the skin

Additionally, recent biological applications and clinical trials are introduced.

\section{Types of microneedles}

Although the microneedle design varies depending on the delivery method, type of microneedle, and action of the drugs to be delivered, most patches have certain common features. A typical microneedle has the shape of a tapered sharp tip with a length of 150-1500 $\mu \mathrm{m}$, a width of 50-250 $\mu \mathrm{m}$, and a tip thickness of 1-25 $\mu \mathrm{m}$ (Waghule et al. 2019). Microneedles are usually made of metal, silicon, polymer, glass, or ceramic. The drug is generally placed in or on the microneedle tip, which is fixed to the base substrate underneath to form an array. The microneedle array is attached to the patch backing for ease of use; this backing includes a skin adhesive to improve contact with the skin. The microneedles are typically classified into four types (Fig. 1). Solid microneedles are primarily made of metal and silicon, which provide strong mechanical properties and do not contain drugs. Therefore, after applying the microneedles, it is necessary to further apply the drug to the area. In contrast, when coated microneedles are applied on the surface of the skin, the drug is delivered simultaneously with the application. In dissolving microneedles, the drug can be included in the biodegradable matrix, in which case no sharp waste is produced after microneedle application. Hydrogel microneedles allow drugs to be delivered slowly because the drug is contained in all areas such as the tip of the microneedle and the patch backing. Since the characteristics of microneedles vary with the type, a suitable

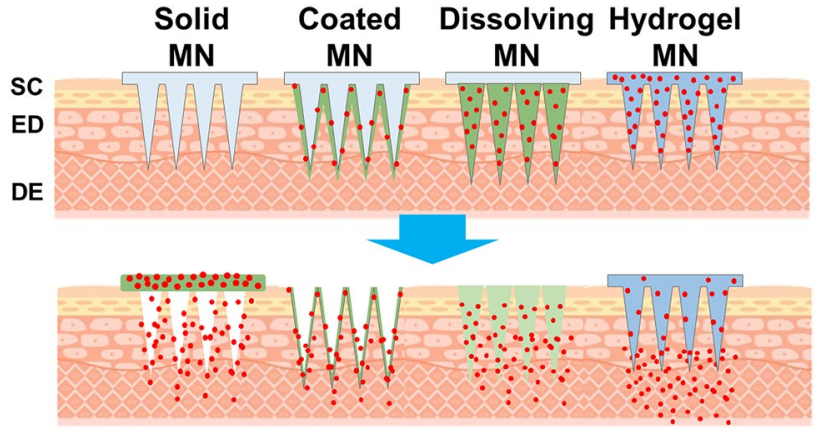

Fig. 1 Schematic illustration of the types of microneedles and their drug delivery methods. $S C$ stratum corneum, $E D$ epidermis, $D E$ dermis, $M N$ microneedles

design should be selected for the microneedles according to the drug dose, onset of action, delivery period, delivery efficiency, packaging, sharp waste, and patch-wearing time (Table 2).

\section{Solid microneedles}

Solid microneedles are an array containing microscale tapered sharp tips composed of a single material without any drugs or excipients, They are inserted into the skin, creating micron-sized pores on the skin surface (Fig. 2a). When the drug is placed on the treated area, the drug passes through the stratum corneum, the largest barrier of the skin, through these pores; it is easily transferred to the capillaries in the superficial dermis, increasing the bioavailability of the drug (Henry et al. 1998). The agent may be formulated 
Table 2 Decision matrix for suitable microneedle design

\begin{tabular}{|c|c|c|c|c|}
\hline $\begin{array}{l}\text { Microneedle type } \\
\text { Decision parameter }\end{array}$ & Solid microneedle & Coated microneedle & Dissolving microneedle & Hydrogel microneedle \\
\hline Drug dose & $\begin{array}{l}\mathrm{O} \\
\text { High }\end{array}$ & $\begin{array}{l}\times \\
\text { Low } \\
\Delta(\text { If several patches are } \\
\text { used })\end{array}$ & $\begin{array}{l}\times \\
\text { Low } \\
\triangle \text { (If several patches are } \\
\text { used) }\end{array}$ & $\begin{array}{l}\mathrm{O} \\
\text { High }\end{array}$ \\
\hline $\begin{array}{l}\text { Onset of action (Pharma- } \\
\text { cokinetics/ pharmacody- } \\
\text { namics) }\end{array}$ & $\begin{array}{l}\times \\
\text { Slow release by diffusion }\end{array}$ & $\begin{array}{l}\bigcirc \\
\text { Rapid dissolution }\end{array}$ & $\begin{array}{l}\text { Dependent on the formula- } \\
\text { tion }\end{array}$ & $\begin{array}{l}\times \\
\text { Slow release by diffusion }\end{array}$ \\
\hline Delivery period & $\begin{array}{l}\Delta \\
\text { Several hours (agents that } \\
\text { keep the pores open } \\
\text { longer are additionally } \\
\text { needed) }\end{array}$ & $\begin{array}{l}\times \\
\text { Several minutes }\end{array}$ & $\begin{array}{l}\text { Several minutes to weeks } \\
\text { (depending on the formu- } \\
\text { lation) }\end{array}$ & $\begin{array}{l}\triangle \\
\text { Several hours }\end{array}$ \\
\hline $\begin{array}{l}\text { Delivery efficiency (Expen- } \\
\text { sive drugs require high } \\
\text { delivery efficiency) }\end{array}$ & $\begin{array}{l}\times \\
\text { Some drug remains in the } \\
\text { patch or formulation }\end{array}$ & O & $\bigcirc$ & $\begin{array}{l}\times \\
\text { Some drug remains in the } \\
\text { patch }\end{array}$ \\
\hline Sharp waste generation & $\mathrm{O}$ & O & $\begin{array}{l}\times \\
\text { No sharp waste }\end{array}$ & $\begin{array}{l}\Delta \\
\text { Swollen hydrogel } \\
\text { microneedle tip }\end{array}$ \\
\hline Packaging & $\begin{array}{l}\Delta \\
\text { Separate packaging for } \\
\text { microneedles and formu- } \\
\text { lation }\end{array}$ & O & O & O \\
\hline Patch-wearing time & $\begin{array}{l}\times \\
\text { Several hours }\end{array}$ & $\begin{array}{l}\bigcirc \\
\text { Several minutes }\end{array}$ & $\begin{array}{l}\bigcirc \\
\text { Several minutes }\end{array}$ & $\begin{array}{l}\times \\
\text { Several hours }\end{array}$ \\
\hline
\end{tabular}

$\mathbf{a}$

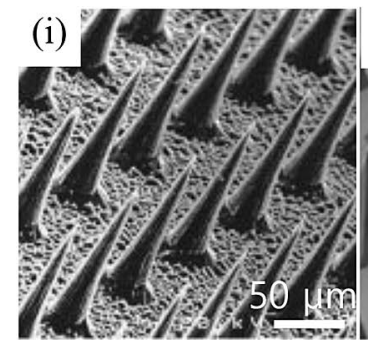

c
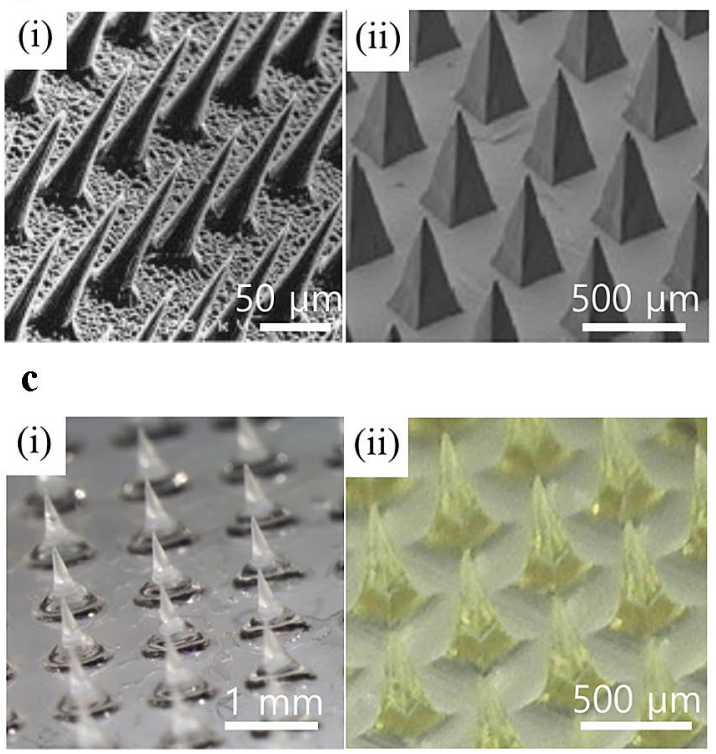

b
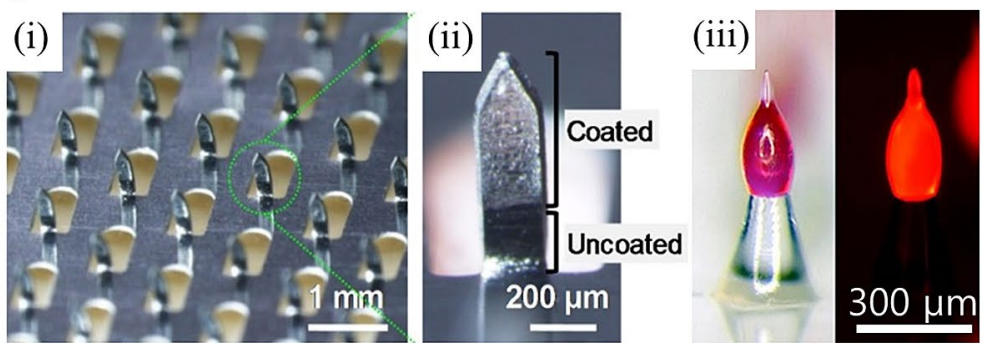

d
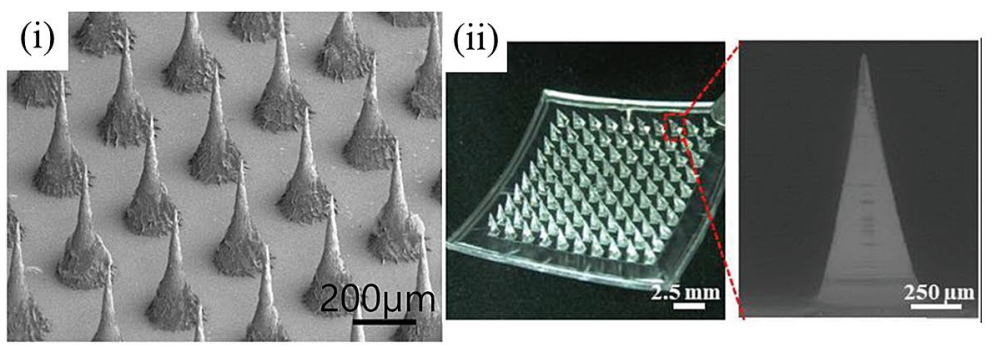

Fig. 2 a Silicon solid microneedles (i (Henry et al. 1998) and ii (Park et al. 2010)), b coated microneedles (i, ii (Shakya et al. 2017) and iii (Chen et al. 2017)), $\mathbf{c}$ dissolving microneedles (i (Tas et al. 2017) and ii (Du et al. 2019)*), and $\mathbf{d}$ hydrogel microneedles (i (Yu et al. 2015)

as a conventional transdermal patch or topical skin formulation (Hoang et al. 2015). Drugs can be delivered over and and ii (He et al. 2020). *Reprinted with permission from (Du H et al. (2019) ACS Appl Mater Interfaces 11:43,588-43,598). Copyright (2019) American Chemical Society

extended time by including reagents that keep the pores open for a longer duration (Brogden et al. 2013). 


\section{Coated microneedles}

In coated microneedles, the surface of a solid microneedle is coated with a water-soluble matrix so that the drug dissolves rapidly into the skin after microneedle insertion (Fig. 2b) (Haj-Ahmad et al. 2015; Jiang et al. 2007). The coating formulation should form a film on the surface of the microneedle and maintain adhesion during storage and insertion into the skin. To achieve this purpose, the coating formulation should have adequate viscosity. The location where the coating formulation is placed should be considered. Generally, it is economical to place the drugs only at the tip where the microneedle enters the actual skin. In the case of dip coating, the drug-coated area can be controlled via regulating the depth to which the microneedle is dipped into the coating formulation (Gill et al. 2007a; Gill et al. 2007b; Shakya et al. 2019). The drug-coated area can be determined by controlling the surface tension of the coating formulation, thus regulating the spreading of the microneedle. In coated microneedles, the drug can quickly dissolve in the skin, resulting in a fast onset of drug action. The thickness of the coating can be increased by repeating the formulation coating; however, it is not suitable for drug delivery as it requires a large dose due to dose limitations (Chen et al. 2017; Waghule et al. 2019).

\section{Dissolving microneedles}

Microneedles themselves can be made of water-soluble or biodegradable materials that contain the drugs and possess sufficient mechanical strength to penetrate the skin (Fig. 2c) (Sullivan et al. 2010). Insertion of a dissolving microneedle into the skin does not generate sharps waste because it rapidly dissolves or disintegrates upon contact with the skin fluid (Edens et al. 2015; Hirobe et al. 2015; Quinn et al. 2015). Dissolving microneedles are primarily manufactured using a water-soluble biodegradable polymer via a solvent casting method. Biodegradable, cellulose-based polymers such as carboxymethyl cellulose (CMC) and methyl cellulose are frequently used. Saccharides (e.g. trehalose and sucrose) are also included in the microneedles; they promote disintegration of the formulation and stabilize biomolecules (Mistillis et al. 2015; Raphael et al. 2016). The formulation of the drug-containing tip should exhibit compatibility with the drug, provide mechanical strength, and have a sufficiently low viscosity for filling the microscale mold space well without air bubbles. The base substrate containing no drug may have a higher viscosity than the tip, may be mechanically weak, or may be a water-insoluble material (Prausnitz 2017).

Recently, several studies have been conducted for shortening the microneedle patch-wearing time via separating the microneedle tips rapidly from the base substrate without needing the tips to fully dissolve in the skin. Li et al. reported a microneedle patch capable of rapidly separating after skin insertion by shearing force. The mechanical strength of the microneedle was controlled by trapping a droplet on the microneedle ( $\mathrm{Li}$ et al. 2019a). In addition, the microneedle tip was separated within 2 min from the base substrate, which was composed of a foamable material (Li et al. 2019b). Jun et al. developed insertion-responsive microneedles for immediate separation of the microneedle after skin application (Jun et al. 2018). A small single wall was designed on the side of the microneedle base; the structure enabled rapid mechanical separation of the tip from base. However, as with dissolving and coated microneedles, this system is disadvantageous for delivering large doses; studies are being conducted for increasing the amount of drug that can be incorporated in these microneedles.

\section{Hydrogel microneedles}

In hydrogel microneedles, the drug is contained in all areas of the microneedle tip, base substrate, and patch backing and is released at a slow rate while the patch is applied to the skin (Fig. 2d). The microneedle patches are primarily composed of hydrogel, and when they encounter fluids in the skin, they are hydrated but not dissolved ( $\mathrm{Al}$ Sulaiman et al. 2019; He et al. 2020; Yu et al. 2015). A high amount of the drug in the hydrogel is delivered to the skin through diffusion (Migdadi et al. 2018; Courtenay et al. 2020). Since the drug can be incorporated in the entire microneedle patch, this system is suitable for large dose delivery; however, its disadvantage is that the patch-wearing time is long because the drug delivery rate is slow.

\section{Materials for microneedles}

Various materials, from metal to polymer, are used in microneedles, depending on the design or components of the patch. Generally, microneedle materials should have sufficient mechanical strength for skin insertion (Dharadhar et al. 2019). Non-dissolving microneedles are inert, biocompatible, and sufficiently strong for skin insertion without causing an immune response. In contrast, the matrices of the coated and dissolving microneedles should generally be water-soluble and biocompatible. In addition, it should dissolve or disintegrate in the body without inducing toxicity. Compatibility between the matrices and drugs is critical during the manufacturing process, storage, and transportation of the microneedle patches. The characteristics of various materials used in microneedles are described below. 


\section{Silicon}

Silicon has sufficient mechanical strength for skin insertion; therefore, it is often used for manufacturing solid and coated microneedles (Hoang et al. 2015; McGrath et al. 2011). Silicon microneedles can be precisely manufactured with small sharp tips with lengths of $100 \mu \mathrm{m}$ or less using deep reactive ion etching and photolithography (Donnelly et al. 2009; Henry et al. 1998; Li et al. 2019c). However, the equipment used is expensive, the process is expensive, and the production speed is slow (Banga 2009). The silicon microneedle can cause safety problems when it breaks from the skin and fragments remain in the tissue (McGrath et al. 2011). Recently, silicon is being used in reverse master molds rather than in solid microneedles (Lutton et al. 2015).

\section{Metal}

Metal materials exhibit high mechanical and tensile strength; therefore, they can easily pass through the skin. They are used to produce solid, coated, and hollow microneedles. In general, stainless steel (Gupta et al. 2011) and titanium (Ti) (Choi et al. 2013; McCarthy et al. 2011; Skoog et al. 2015) are typical metal materials used in microneedles. Stainless steel is the most used metal material for microneedle production; however, it exhibits a faster corrosion rate than Ti alloy (Amalraju et al. 2012). Ti alloys possess stronger mechanical strength than stainless steel; however, they are more expensive (Amalraju et al. 2012).

\section{Polymer}

The polymers used for microneedle manufacture should be water-soluble, biocompatible, and mechanically strong for skin insertion (Praustniz 2017). The most common method for producing polymer microneedle is the solvent casting method. This method involves obtaining an inverse mold from the microneedle structure, pouring a polymer formulation on it, drying it, and peeling it from the inverse mold. Dissolving or hydrogel microneedles are manufactured using the solvent casting method with various types of polymers such as hydroxypropyl methylcellulose (Kim et al. 2016), hyaluronic acid (Du et al. 2019), CMC (Mistillis et al. 2015), polyvinyl pyrrolidone (Caffarel-Salvador et al. 2015; Tang et al. 2018; Tas et al. 2017), and poly(lactic-co-glycolic acid) (PLGA) (Li et al. 2019c).

\section{Glass}

Glass microneedles are primarily hollow and prepared using wet etching or micropipette puller (Dharadhar et al. 2019; Martanto et al. 2006). It exhibits sufficient strength for skin insertion, enabling easy processing of the tapered shape. It is easy to sterilize because it is stable at high temperature and pressure; the material itself is biocompatible. However, it breaks easily; specifically, if the tip of the microneedle is broken and it remains in the skin tissue, it can cause inflammation or granulomas.

\section{Ceramic}

Since ceramic materials such as alumina, calcium phosphate, and calcium sulphate exhibit biocompatibility and provide sufficient mechanical strength, studies have explored their use in the preparation of microneedles (Ita 2018) (Figure. 3).

\section{Microneedle fabrication techniques}

When designing a microneedle, the objective of the microneedle is considered first. The drug type and dose, desirable pharmacokinetics/pharmacodynamics, and targets for use are considered. Next, the most optimized microneedle design and materials are determined. The manufacturing method for microneedles varies depending on the design or material. When focusing on the economic aspect, a method such as solvent casting, which is easy to set up, is used. In contrast, if the focus is on the accuracy, precision, and reproducibility of needle production, production of metal or silicon microneedles based on MEMS technology can be considered. We have summarized various methods reported till date for microneedle manufacture.

\section{Laser-mediated fabrication techniques}

\section{Laser cutting}

Laser cutting is primarily used for manufacturing a metal or polymer microneedle; the most used material is stainless steel (Banks et al. 2010; Martanto et al. 2004; McAllister et al. 2003). The 2D shape of a microneedle is generated through cutting on a flat metallic sheet using a laser. The size and orientation of the microneedle array is designed through a computer-aided design (CAD) software. The microneedle drawn in $2 \mathrm{D}$ is bent by 90 degrees to create a $3 \mathrm{D}$ microneedle. Needle tips or rough surfaces can be cleaned using electropolishing (Gill et al. 2007a; Gill et al. 2007b; Shakya et al. 2019).

\section{Laser ablation}

Laser ablation is also used for fabricating metal or polymer microneedles (Nejad et al. 2018). Laser cutting involves cutting a metal or polymer plate into a $2 \mathrm{D}$ shape, whereas laser ablation engraves the plate into a 3D shape. Basically, when the substrate is irradiated with a laser beam (e.g., $\mathrm{CO}_{2}$ laser 
a
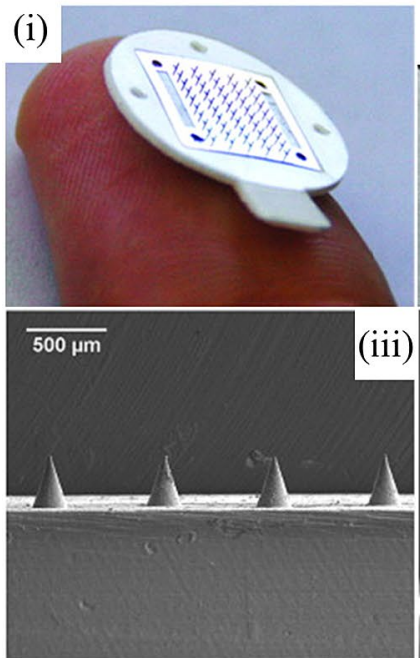
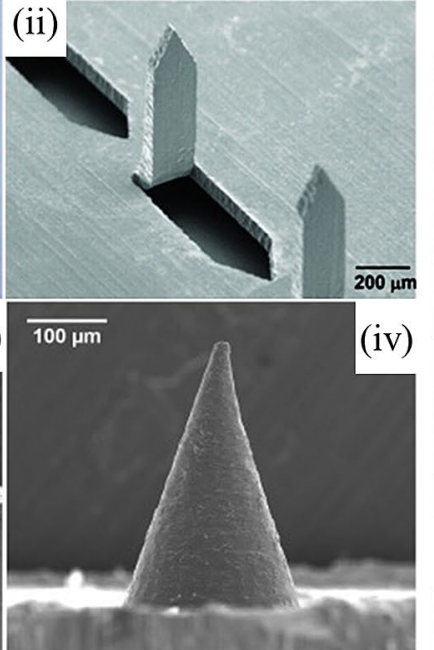

b

(i)
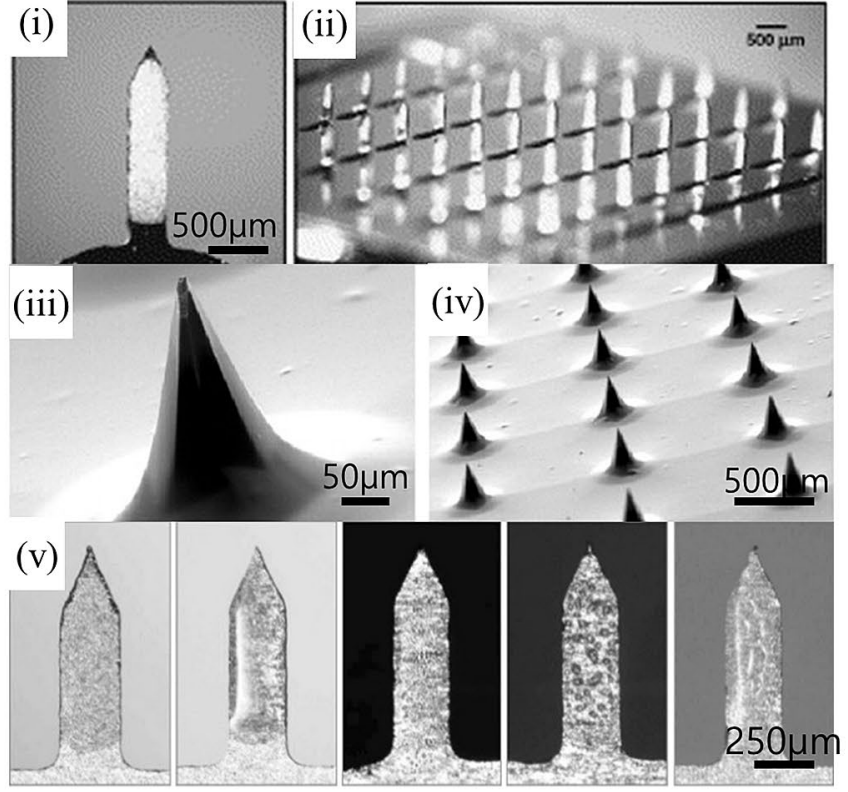

d

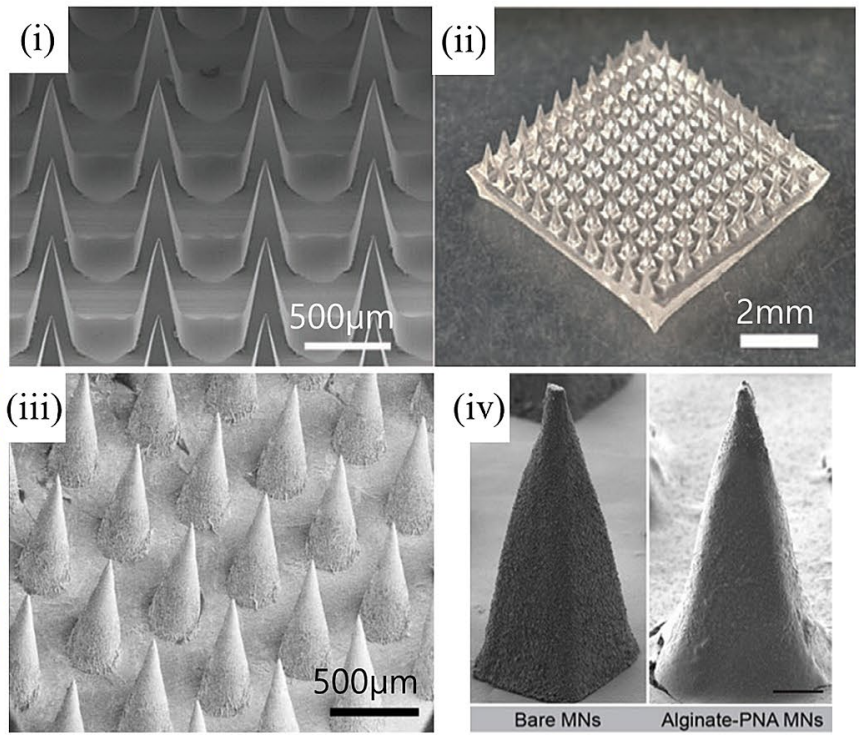

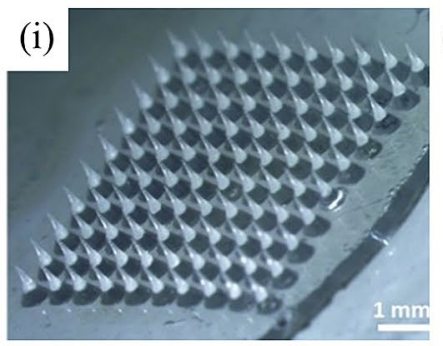

(iii)

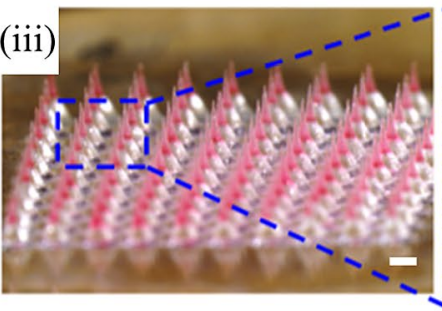

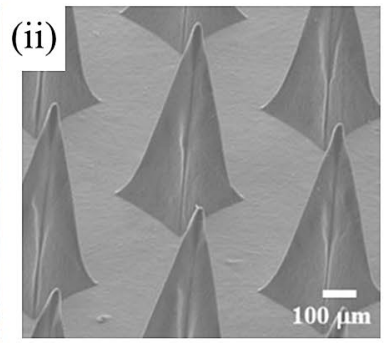

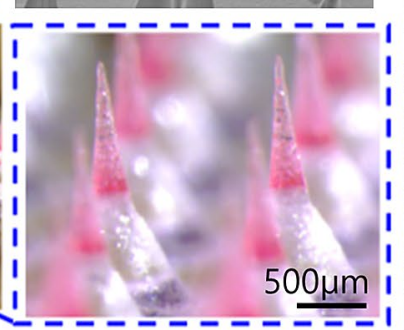

Fig. 3 a Solid microneedles composed of stainless steel (i and ii) (Gupta et al. 2011) and titanium (iii and iv) (Skoog et al. 2015). b Coated microneedles composed of stainless steel (i and ii) (Gill et al. 2007), silicon (iii and iv) (McGrath et al. 2011), and titanium (v) (Choi et al. 2013). c Dissolving microneedles composed of CMC (i) (Perez Cuevas et al. 2018), HPMC (ii) (Kim et al., 2016), and PLGA (iii) (Li et al. 2019b)*. d Hydrogel microneedles composed of HA (i and ii) (Zheng et al. 2020), PVA (iii) (Tang et al. 2018)**, and alginate (iv) (Al Sulaiman et al. 2019)***.*Reprinted/adapted from [ $\mathrm{Li}$ et al., Science Advances 2019 5:1-12] (C) The Authors, some rights reserved; exclusive licensee American Association for the Advance-

beam), it absorbs the laser energy and heats, resulting in its evaporation or sublimation. Through this process, an inverse mold can be produced by generating a microneedle pattern. ment of Science. Distributed under a Creative Commons Attribution NonCommercial License 4.0 (CC BY-NC) http://creativecommons .org/licenses/by-nc/4.0/. **Reprinted/adapted from [Tang et al., Science Advances 2018 4:eaat9365] () The Authors, some rights reserved; exclusive licensee American Association for the Advancement of Science. Distributed under a Creative Commons Attribution NonCommercial License 4.0 (CC BY-NC) http://creativecommons .org/licenses/by-nc/4.0/. ***Reprinted with permission from (Al Sulaiman et al. ACS Nano 13:9620-9628). Copyright (2019) American Chemical Society

\section{Photolithography}

Photolithography is used to elaborately create solid or hollow microneedles. This method is used to manufacture 
silicon microneedles or dissolving/hydrogel microneedles via making an inverse mold based on the microneedle structure. When fabricating silicon microneedles using photolithography, a sacrificial layer is deposited in the form of a thin film on cleanly treated silicon. Subsequently, a photoresist, a photosensitive polymer, is coated on the silicon via spin coating. If the photomask with desirable pattern is aligned on the substrate and exposed to strong UV radiation, the desired pattern is generated in the part exposed or not exposed. The pattern is generated in the photoresist through the development process; subsequently, the exposed substrate without the photoresist is etched through the etching step. Consequently, a desirable pattern is transferred from the photomask to the photoresist to the silicon (Dardano et al. 2015; Dharadhar et al. 2019).

\section{Etching}

When a microneedle is fabricated using general photolithography, etching is an important process for determining the tapered shape of the microneedle tip. Before the etching process, the size of the microneedle base and the gap among the microneedles are determined. Subsequently, the length and shape of the microneedles are determined through the etching process (Wilke et al. 2005). The etching process is classified as dry etching and wet etching. It results in isotropic or anisotropic etching, depending on the method utilized.

\section{Dry etching}

Dry etching is primarily used to create solid or hollow microneedles. It is classified into physical methods and chemical methods. Physical methods include ion milling and sputtering (Indermun et al. 2014; Kim et al. 2012). In dry etching, an inert gas (e.g., Ar or $\mathrm{SF}_{6}$ ) is ionized by high energy and unidirectional electrodes. Because the ions strike the silicon substrate at a high speed in a single direction, anisotropic etching is performed. In the manufacturing process, the area protected by the oxide film (sacrificial layer) or photoresist is hardly etched, while the area exposed on the silicon is etched. Chemical methods include high pressure plasma etching, in which a chemically reactive plasma gas is generated using strong energy. The plasma reacts with the surface of the substrate, and it is converted into a volatile material, which is blown away, thereby resulting in isotropic etching of the substrate. Reactive ion etching combines physical and chemical methods; both plasma and sputter etching can be used to control isotropic and anisotropic etching (McAllister et al. 2003). Through the optimization of this process, a precise microneedle sharp tip can be manufactured (Henry et al. 1998).

\section{Wet etching}

Wet etching is also used for fabrication of metal or silicon microneedles (Wilke et al. 2005). In this process, a pattern is produced on the substrate using a chemical etchant. In the case of a silicon wafer, a potassium hydroxide aqueous solution is used; a sharp tip shape can be produced by applying different rates of etching, depending on the direction of the silicon crystals (Henry et al. 1998; Indermun et al. 2014). Wet etching is primarily isotropic etching via a chemical reaction; the etching rate is significantly faster than that in dry etching. Although the cost required for the entire process is low, the poor accuracy of this method is a disadvantage for the fabrication of fine patterns (Figure. 4).

\section{D printing (additive manufacturing)}

3D printing is an additive processing technology that rapidly prototypes a design at low cost and high throughput (Ogundele et al. 2017). Recently, the 3D printing technology has been expanded to include the production of microstructures such as microneedles (Park et al. 2019; Economidou et al. 2018). The existing manufacturing technology is limited to the production of a simple structured microneedle, while the new 3D printing technology can produce a more sophisticated and complex-shaped microneedle structure (Han et al. 2020). Microneedles are manufactured using high precision stereolithography (SLA), digital light processing (DLP) method, or fused deposition modeling (FDM) (Krieger et al. 2019; Johnson et al. 2019; Luzuriaga et al. 2018).

\section{Microstereolithography $(\mu \mathrm{SL})$}

$\mu \mathrm{SL}$ has been widely used in the production of tissue scaffolds, nerve guidance conduits, and cardiovascular stents in biomedical and tissue engineering (Dharadhar et al. 2019). The manufacturing of 3D objects using the $\mu \mathrm{SL}$ method is based on the photopolymerization of a liquid resin using a light source such as UV radiation and the process of controlling the space to manufacture the 3D object. The building stage and laser beam or digital light projector are precisely controlled by a computer so that the light is illuminated on the resin surface. A layer-by-layer is created on the surface of the building platform, forming the structure (Krieger et al. 2019; Melchles et al. 2010). A microneedle based on poly(propylene fumarate) was prepared using $\mu$ SL technology for the treatment of skin cancer. To improve mechanical strength, a biodegradable polymer, poly(propylene fumarate), was mixed with diethyl fumarate ( $\mathrm{Lu}$ et al. 2015). This microneedle system enabled controlled release 
a

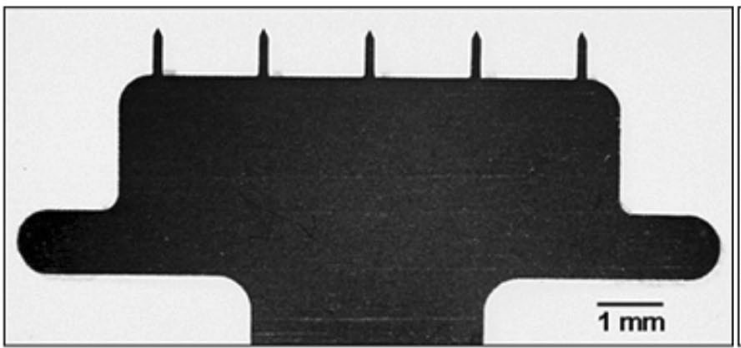

c

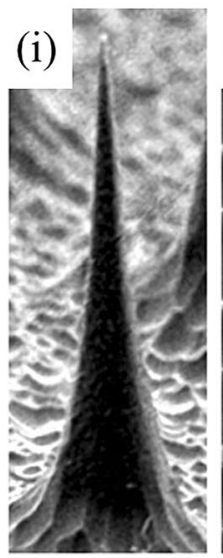

b
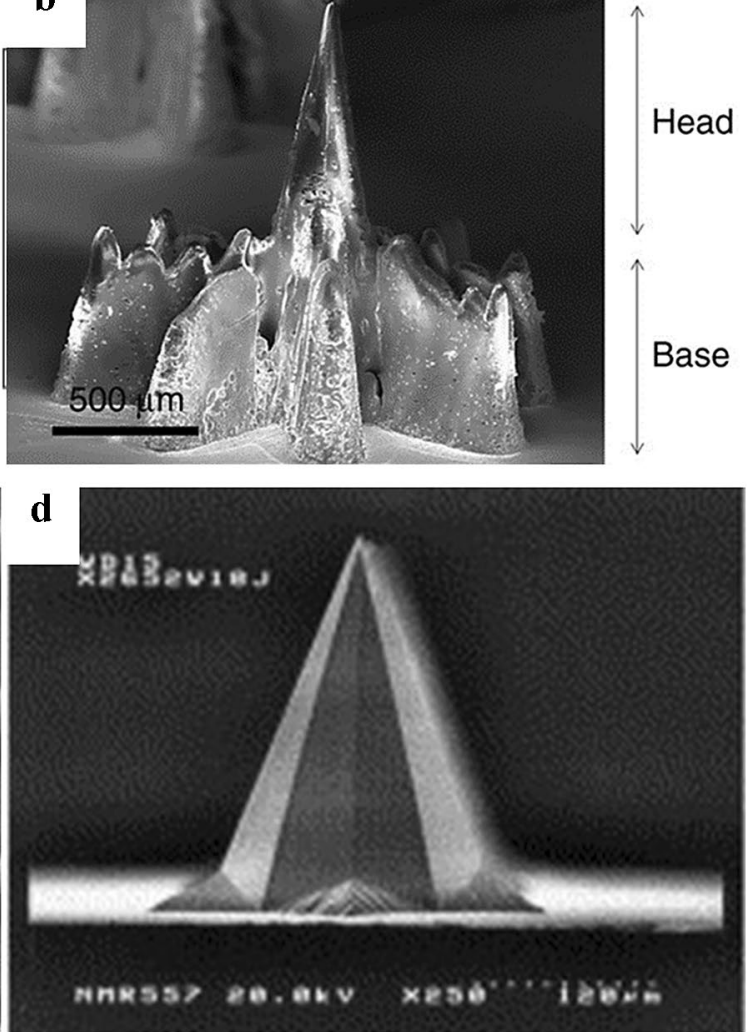

Fig. 4 Microneedles fabricated using a laser cutting (Banks et al. 2010), b laser ablation (Nejad et al. 2018), c photolithography dry etching (i and ii) (McAllister et al. 2003)*, and d wet etching (Wilke et al. 2005). *Copyright (2003) National Academy of Sciences, U.S.A

of dacarbazine, an anti-cancer drug, for 5 weeks through modification of the drug dose and molecular weight of the polymer monomer (Lu et al. 2015).

\section{Continuous liquid interface production (CLIP)}

CLIP is different from the traditional layer-by-layer approach to additive manufacturing. CLIP fabricates an object through photopolymerization of a photoreactive resin using the light reflected from a general DLP chip (Johnson et al. 2016). The basic principle of the CLIP is the same as that for the DLP method; however, CLIP addresses the problem of peeling of the cured resin layer. Because the separation and rearrangement steps, which are rate limiting in the conventional process, have been eliminated, the microneedle could be produced in approximately 2 to $10 \mathrm{~min}$ (i.e., reducing the output time by approximately 25 to 100 times compared to that for the conventional method) (Schmidleithner et al. 2018). Johnson et al. reported CLIP-based production of microneedle arrays using biocompatible polymers (e.g., trimethylolpropane triacrylate, polyethylene glycol dimethacrylate, polycaprolactone trimethacrylate, and polyacrylic acid) (Johnson et al. 2016).

\section{Two-photon polymerization (TPP)}

TPP is a sophisticated additive manufacturing method with a resolution of approximately $100 \mathrm{~nm}$ (Takada et al. 2005). TPP initiates polymerization of the resin through multiphoton absorption, which occurs through excitation of the photoinitiator. TPP employs a near-infrared wavelength laser, such as a titanium-sapphire laser, instead of UV light. In the TPP method, unlike in the conventional SLA method, the curing reaction does not occur in the illumination path of the entire laser beam but only at the focal point (Serbin et al. 2003). Therefore, it is possible to manufacture elaborate and complex 3D structures (Balmert et al. 2020; Park et al. 2009) (Figure. 5).

\section{Drug delivery by microneedles}

\section{Proteins}

Protein drugs can be applied to various cancer treatments, vaccinations, and treatment of genetic diseases. Rapid development is expected; however, drug delivery is limited due to the problems of low stability and absorption. For 

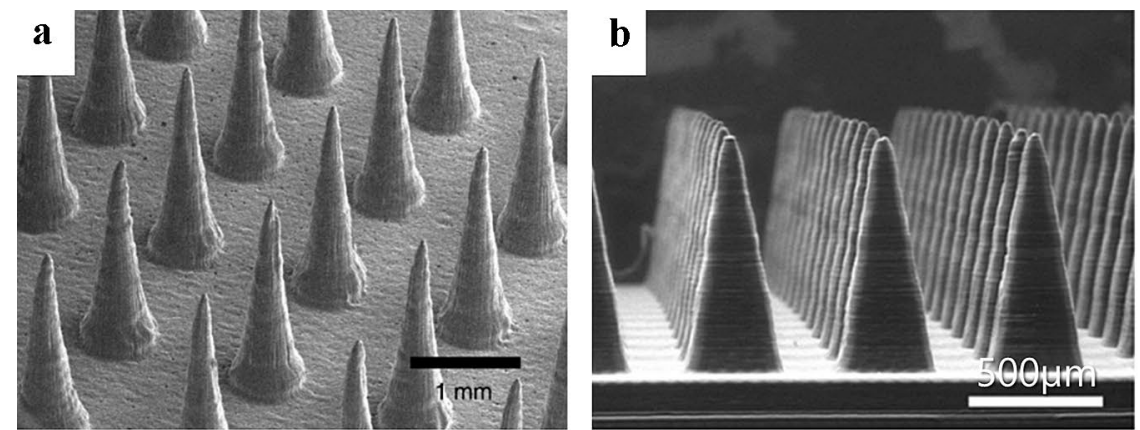

d
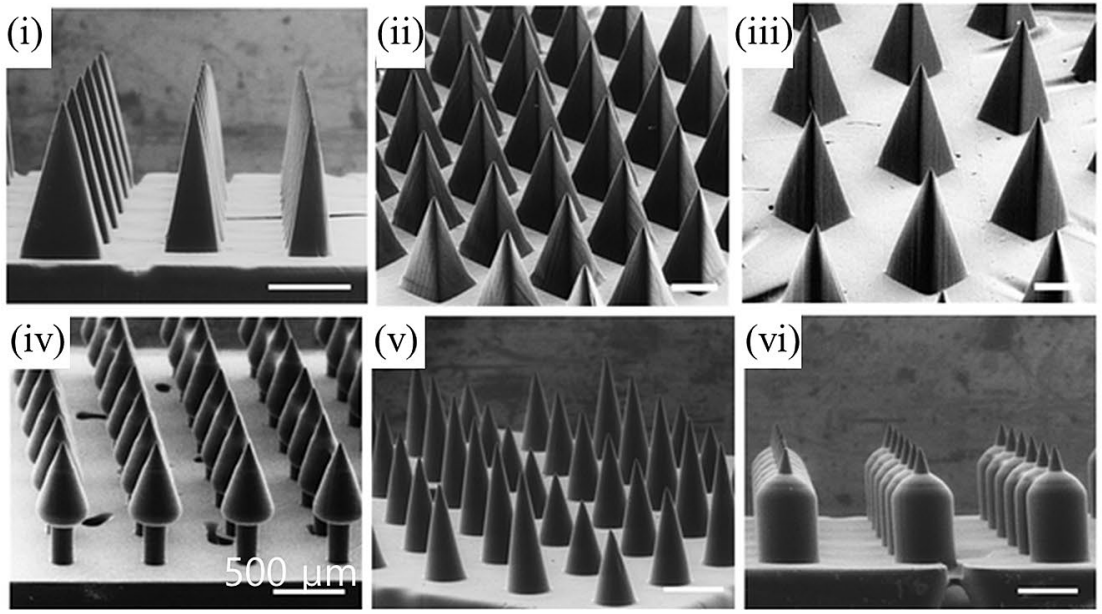

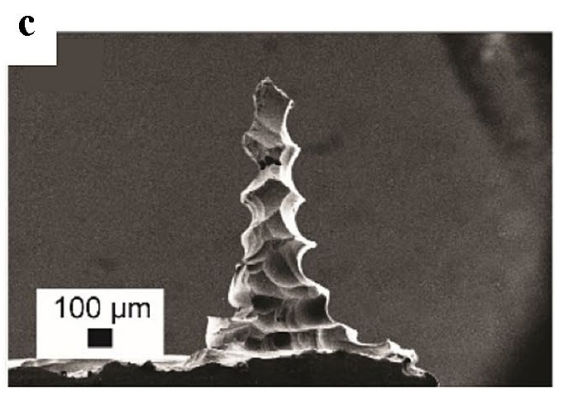

$\mathbf{e}$
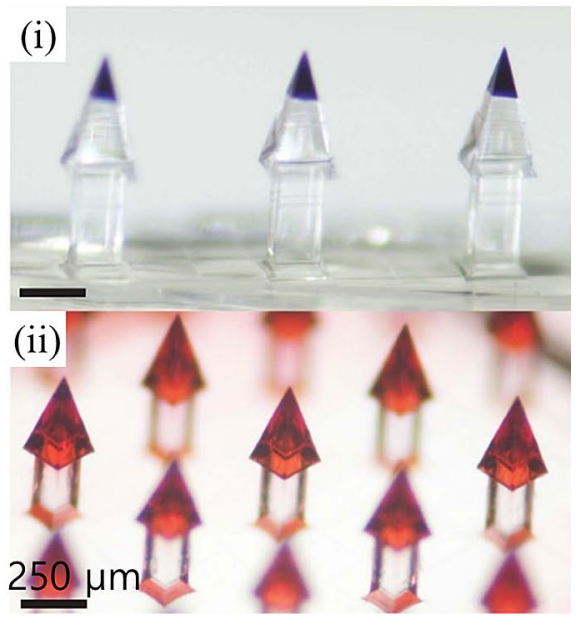

Fig. 5 Microneedles fabricated by 3D printing: a SLA (Krieger et al. 2019), b DLP (Johnson et al. 2019), c FDM (Luzuriaga et al. 2018), d CLIP (i to vi) (Johnson et al. 2016), and e TPP (i and ii) (Balmert et al. 2020)

example, during dosing and storage, protein denaturation, drug absorption efficiency, and cellular permeability related to molecular size can lead to limited therapeutic efficiency. Microneedle research is being conducted for improving the delivery efficiency of protein drugs. For example, microneedle technology has been developed for proteins including insulin, desmopressin, erythropoietin, lysozyme, glucagon, glucagon-like peptide-1, parathyroid hormone, and growth hormone. The selection of materials and formulations for preserving protein drug stability remains a difficult task, especially in large-scale storage planning and production chains for clinical use. Chen et al. reported a microneedle with glucose response and temperature stability that was developed using phenylboronic acid for insulin drug delivery in diabetes treatment (Chen et al. 2020). Lahiji et al. evaluated the effects of microneedle manufacturing parameters including manufacturing and storage temperature and drying conditions so that the combination of low temperature during manufacture, mild drying conditions, polymer concentration, and addition of protein stabilizer maintains lysozyme activity up to $99.8 \pm 3.8 \%$. Additionally, they reported the importance of optimizing manufacturing parameters (Lahiji et al. 2018).

\section{Vaccines/antibodies}

Current vaccines are usually limited to subcutaneous injection. Microneedles containing vaccines have been studied recently for induction of an antibody immune response. The advantage of microneedle vaccines is that they enable stronger local immunity compared to injectable formulations because they induce antigen presentation to dendritic cells residing in the skin. Currently, the availability of vaccines is often dependent on cold storage and transportation. Vaccine development using microneedles can preserve the long-term antigenic immunogenicity of the patch and allow flexible storage conditions. Additionally, monoclonal antibodies target specific cells and modulate the immune system, rendering them useful in a wide range of diagnostic and therapeutic applications. Local delivery of monoclonal antibodies using microneedles was performed for alleviating excessive stimulation of autoreactive $\mathrm{T}$ cells and addressing side effects (Xu et al. 2017). Antibody delivery can pose various challenges, including loss of efficacy and risk of immunogenicity due to protein inactivation. To address this problem, stability of the antibody in the microneedle is important. 
Zhu et al. investigated the stability of a vaccine-loaded microneedle and observed that trehalose, during the microneedle manufacturing process, showed significantly higher stability compared to sucrose and that $80 \%$ of the initial antigenicity was retained under stress conditions $\left(60{ }^{\circ} \mathrm{C} / 3\right.$ months) (Zhu et al. 2019). To further increase immunogenicity, an immunomodulatory cytokine, granulocyte-macrophage colony stimulating factor (GM-CSF), was applied to microneedles to induce a long-lived antibody response. For stable delivery of GM-CSF, a microneedle using trehalose, CMC, or gelatin was used (Littauer et al. 2018). A third-generation hepatitis vaccine microneedle containing $15 \%$ trehalose exhibited increased stability compared to conventional liquid formulations, including stability for 7 days at $40{ }^{\circ} \mathrm{C}$ and improved stability during freeze-thaw cycles (Nguyen et al. 2019).

\section{Clinical studies}

Till date, studies on various aspects of microneedles, ranging from manufacturing technologies to in vitro and in vivo transdermal drug delivery, have been widely performed, demonstrating the potential applicability of microneedles in medicine. In addition, the safety and efficacy of microneedles have been proved in recent clinical trials performed under various conditions.

Griffin et al. (2017) conducted a clinical trial evaluating uncoated microneedles and excipient-coated microneedles in 18 healthy volunteers aged $18-45$ years. This trial utilized a $10 \times 10 \mathrm{~mm}$ silicon microneedle system with microprojection arrays of $250 \mu \mathrm{m}$ length. The results showed that the microneedles did not induce any unexpected side effects and only resulted in a low level of pain. (Arya et al. 2017) conducted a clinical trial on microneedles alone in 15 healthy volunteers aged $18-57$ years. The trial used dissolving microneedles containing 100 conical microneedles with a height of $650 \mu \mathrm{m}$ and base diameter of $200 \mu \mathrm{m}$. The microneedle was well tolerated in the skin with no pain or swelling and only mild erythema. (Ono et al. 2017) conducted a clinical trial on a microneedle system alone in 10 healthy volunteers aged 20-60 years. Two types of microneedles were used: microneedles composed of polyglycolic acid and Nylon-6 with a patch area of $0.785 \mathrm{~cm}^{2}$. The results demonstrated that the microneedles were safely applied to human skin as no broken microneedles or significant irritation was observed after application.

Fernando et al. (2018) conducted clinical trials comparing the immunogenicity of inactivated influenza virus-coated microneedles and intramuscular (IM) injections of the same inactivated influenza virus against an influenza vaccine in 61 healthy volunteers aged $18-45$ years. The trial used a $10 \times 10 \mathrm{~mm}$ coated silicon microneedle with microprojection arrays $\left(10,000 / \mathrm{cm}^{2}\right)$ of $250 \mu \mathrm{m}$ length. The microneedle vaccination was demonstrated to be safe and acceptable, and it elicited an immune response similar to that induced by the IM injection. Side effects were mild or moderate. Rouphael et al. (2017) conducted a phase 1 trial in human subjects using microneedles for the transdermal delivery of inactivated influenza vaccine. No serious side effects were associated with microneedle treatment, and the mean titers reported in participants who received the microneedle patch were similar to that in individuals who received the IM injection. Several clinical studies on microneedle-mediated vaccine delivery have been completed (Zheng et al. 2018). However, the number of clinical trials on microneedle vaccines was considerably less than that for other routes of administration. The side effects of microneedle-mediated vaccine delivery have been shown to be mild and transient after administration, and patients have shown increased neutralizing antibody titers, serum conversion, and serum protection levels, similar to that with IM injection. However, vaccines for microneedles have not been approved till date (Zheng et al. 2018).

Lee et al. (2018) evaluated microneedles for the treatment of psoriatic plaques in 10 volunteers aged 21-69 years of age. They used a hyaluronic acid-based $2.6 \times 2.6 \mathrm{~mm}$ microneedle system with 76 circular cone-shape microneedles $650 \mu \mathrm{m}$ in height. In this study, the application of the microneedle significantly improved the resolution of psoriasis plaques resistant to topical ointments.

Petukhova et al. (2017) studied microneedle-assisted photodynamic treatment of actinic keratoses using a microneedle roller in 33 volunteers. They utilized a single-use sterile array with a length of $200 \mu \mathrm{m}$. In this study, photodynamic treatment through pretreatment using the microneedle device showed efficacy similar to that with the conventional treatment. An additional advantage was that there was little pain.

Akilov et al. (2018) studied the treatment of warts using doxorubicin-loaded microneedles in 11 volunteers. The purpose of this study was to establish a safe dose of doxorubicin when delivered through the microneedles. Through this phase I clinical trial, they made good progress in setting the dose for the microneedles as $100 \mathrm{mg}$ of doxorubicin.

Ryu et al. (2018) evaluated the treatment of mycosis fungoides using bleomycin-coated polylactic acid microneedles in 42 volunteers. According to the results, there was no significant difference between the microneedle treatment and the conventional treatment regimen. In addition, the decrease in the average size of all warts was approximately the same at 8 and 16 weeks after initial treatment. Therefore, the therapeutic efficacy of the microneedle was similar to that of the conventional treatment. However, the microneedle treatment resulted in significantly less pain than the conventional treatment $(\mathrm{p}<0.001)$.

Tan et al. (2019) studied the treatment of keloids using in 28 volunteers in a phase 1 trial and 17 volunteers in 
a phase two trial. They utilized hyaluronic acid-based microneedles with $14 \times 14$ arrays of $600 \mu \mathrm{m}$ length and showed that the application of microneedles containing triamcinolone once a day significantly reduced the number of keloids. It has been reported that treatment with a microneedle system can serve as an alternative when conventional treatments are unsuitable for the patient.

Spierings et al. (2018) conducted a clinical trial to evaluate the safety and efficacy of zolmitriptan microneedles for the treatment of migraine headaches. The study was a multicenter, randomized, double-blind, placebocontrolled, parallel group phase $2 \mathrm{~b} / 3$ study conducted at 36 locations in the United States. Zolmitriptan-loaded microneedles provided effective relief against migrainerelated headaches and related symptoms compared to the placebo and demonstrated excellent tolerability.

In the cosmetics field, several clinical studies have been conducted on microneedles. Yang et al. (2019) evaluated skin restoration and wrinkle improvement using $5 \times 5$ arrays of dissolving microneedles containing horse oil (HOS) and/or adenosine (AD). The study showed that the HOS-AD-microneedle significantly improved skin elasticity, hydration, skin density, and wrinkles compared to the AD microneedle, without any side effects. Kang et al. (2019) evaluated skin parameters such as wrinkles, dermal density, elasticity, and hydration following combinatorial application of dissolving microneedles and cream with adenosine (AD). They used $7 \times 7$ arrays of dissolving microneedles in this study. The combination therapy showed statistically significant efficacy in improving the average wrinkle depth, skin density, elasticity, and hydration. No adverse effects on the skin were observed during the trial period. Avcil et al. (2020) studied restoration of skin properties including hydration, wrinkle reduction, density, and thickness using hyaluronic acid-based microneedle containing bioactive peptides in 20 volunteers aged 40-71 years. The microneedles showed excellent resistance and effectiveness; no primary or cumulative skin reactions were reported in any of the subjects. Fine lines/ wrinkles were noticeably reduced by $25.8 \%$. Skin hydration measurements demonstrated a $15.4 \%$ improvement. Dermal skin density and thickness increased by $14.2 \%$ and $12.9 \%$, respectively. In addition to these studies, clinical trials over the past few years have demonstrated the application of microneedles beyond the cosmetic field, including chemical keratos, pigment disorders, hyperhidrosis, and striae (Iriarte et al. 2017).

The application of microneedles in human subjects showed no signs of redness, erythema, or edema. The safe and painless microneedle technology offers an interesting opportunity for transdermal delivery compared to injections.

\section{Limitations and perspectives}

Microneedles are a transdermal drug delivery system that is rapidly growing in research owing to the benefit of increasing patient access to drugs through replacing other routes of administration. Microneedles have been proven to improve drug stability and drug delivery efficacy through non-clinical and clinical studies. However, microneedles as a tool for drug delivery has limitations.

\section{Limited drug dose}

Because of their small size, microneedles can deliver only a limited amount of drugs. Therefore, their application is difficult when a large dose or continuous drug release is required. To overcome this limitation, the immediate limitations can be overcome through applying several patches at once or periodically changing the microneedle patch. However, for expanding the scope of microneedles in medicine, research is needed on increasing the drug dose that can be incorporated in the microneedles.

\section{Solubilizing technology for poorly soluble drugs}

Solubilization of poorly soluble drugs is an essential technology for solving the problem of small-dose microneedles. Basically, sufficient drug solubility in an aqueous solution is required to apply the drug to a microneedle. However, since several drugs show low water solubility, only a small proportion of the drugs can be delivered (Kearney et al. 2019). Increasing the solubility of a poorly soluble drug allows a large dose of the drug to be contained in the same formulation, enabling the incorporation of higher amounts of drugs in microneedles of limited size. Use of prodrugs for increasing solubilization is a representative technique for solubilizing poorly soluble drugs. In addition, there has been consistent research on improving the solubility of poorly soluble drugs using surfactants or liposomes, salt preparation of the drug, $\mathrm{pH}$ adjustment, and nanoparticle control technology.

\section{Sustained drug-releasing technology}

Till date, research on microneedle-based drug delivery has focused on demonstrating rapid dissolution of drug formulations from the microneedles into the body. Thus, although microneedles are effective for single drug administrations, they have limitations in continuous drug delivery. To demonstrate sustained drug release using microneedles, separable microneedles have been developed. Since Chu et al. first developed separable microneedles (Chu et al. 2011), various studies on separable microneedles have been conducted for 
minimizing the patch-wearing time through rapidly separating the formulation from the microneedle. (Choi et al. 2018; Li et al. 2019a, 2019b). In addition, research is being conducted on introducing a sustained-release formulation technology for enabling long-term drug delivery of drugs separated from the microneedle to the body. Li et al. have developed a separable microneedle to release contraceptive hormones and maintain their levels within the therapeutic range for approximately a month (Li et al. 2019a, 2019b). Through research on formulation technology for long-term drug delivery, various drugs can be applied to microneedle patches and various incrementally modified drugs can be developed by enabling effective drug delivery. In addition, it is necessary to develop an adhesive patch that does not cause toxicity even when wearing a microneedle patch for a long duration.

\section{Fabrication technology}

Microneedle master molds are primarily manufactured by deep reactive ion etching for fabricating the small microneedle tips, the size of which ranges over several tens of micrometers with high accuracy and reproducibility. Because the instrument and maintenance are expensive, the barrier to enter the field of microneedle research is high, and the technology of mass production has been limited to certain companies.

\section{D printing}

As the technology for 3D printing advances, microneedle manufacturing has been conducted using entry-level 3D printers. Because the price and maintenance of 3D printers are inexpensive, they can be easily utilized for various applications. CAD software enables the design of novel shapes of microneedles. 3D printing can significantly shorten the product development time due to rapid fabrication and modification of the prototypes. However, there is a limit to the materials that can be used, and the low resolution of entrylevel 3D printers remains a problem. Although there are high-resolution 3D printers, the instrument price is high. Nevertheless, 3D printing studies have continued to overcome the limitations. It is expected that the 3D printing technology will enable us to produce customized microneedle patches depending on individual symptoms.

\section{Regulations}

Currently, the licensing of microneedle products is processed for each application rather than for a specific microneedle system (product-specific approval). Therefore, the licensing of microneedle products is delayed, which is a factor restricting the commercialization of microneedles. To address this problem, a microneedle-based licensing regulation including the shape, formulation, sterilization, and packaging of the microneedle must be defined. Through the unification of cGMP and quality control, a microneedle licensing method based on quality by design should be established to promote the commercialization of microneedle products as pharmaceuticals.

\section{Convergence with digital technology}

Current microneedles are designed as simple patches for delivering drugs; however, in the future, they can be developed as digital medicine through fusion with information technology. Convergence systems that provide information on the drug-loading amount, patch-changing time, or rate of controlled drug release can be developed. The convergence technology can contribute to maximizing the drug delivery application of microneedles and diversifying the products.

\section{Conclusion}

Microneedles are a transdermal drug delivery system that is rapidly growing in research owing to the benefit of increasing patient access to drugs through replacing other routes of administration. Microneedles can be classified as solid, coating, dissolving, and hydrogel formulations. They are composed of various materials such as silicon, metal, polymer, glass, and ceramic. Various manufacturing techniques are utilized for imparting unique shapes, sizes, and properties. Microneedles continue to evolve through clinical trials and utilize various drugs. Most studies have demonstrated favorable results using this system. This technique has the potential to provide therapeutic effects in multiple fields.

Acknowledgements This research was supported by a grant (16173MFDS542) from Ministry of Food and Drug Safety in 2020.

\section{Compliance with ethical standards}

Conflict of interest All authors (J.H. Jung and S.G. Jin) declare that they have no conflict of interest.

Statement of human and animal rights This article does not contain any studies with human and animal subjects performed by any of the authors.

\section{References}

Akilov O, McCann S, Erdos G, Falo LD (2018) Phase 1, single-arm, open-label, dose escalation trial of microneedle array-doxorubicin in patients with mycosis fungoides. Eur J Cancer 101:S32 
Al Sulaiman D, Chang JYH, Bennett NR, Topouzi H, Higgins CA, Irvine DJ, Ladame S (2019) Hydrogel-coated microneedle arrays for minimally invasive sampling and sensing of specific circulating nucleic acids from skin interstitial fluid. ACS Nano 13:9620-9628

Amalraju D, Dawood AS (2012) Mechanical strength evaluation analysis of stainless steel and titanium locking plate for femur bone fracture. Eng Sci Technol Int J 2:2250-3498

Arya J, Henry S, Kalluri H, McAllister DV, Pewin WP, Prausnitz MR (2017) Tolerability, usability and acceptability of dissolving microneedle patch administration in human subjects. Biomaterials $128: 1-7$

Avcil M, Akman G, Klokkers J, Jeong D, Çelik A (2020) Efficacy of bioactive peptides loaded on hyaluronic acid microneedle patches: A monocentric clinical study. J Cosmet Dermatol 19:328-337

Balmert SC, Carey CD, Falo GD, Sethi SK, Erdos G, Korkmaz E, Falo LD Jr (2020) Dissolving undercut microneedle arrays for multicomponent cutaneous vaccination. J Control Release 317:336-346

Banga AK (2009) Microporation applications for enhancing drug delivery. Expert Opin Drug Deliv 6:343-354

Banks SL, Pinninti RR, Gill HS, Paudel KS, Crooks PA, Brogden NK, Prausnitz MR, Stinchcomb AL (2010) Transdermal delivery of naltrexol and skin permeability lifetime after microneedle treatment in hairless guinea pigs. J Pharma Sci 99:3072-3080

Bhatnagar S, Dave K, Venuganti VVK (2017) Microneedles in the clinic. J Control Release 260:164-182

Brogden NK, Banks SL, Crofford LJ, Stinchcomb AL (2013) Diclofenac enables unprecedented weeklong microneedleenhanced delivery of a skin impermeablemedication in humans. Pharm Res 30:1947-1955

Caffarel-Salvador E, Tuan-Mahmood T-M, McElnay JC, McCarthy HO, Mooney K, Woolfson AD, Donnelly RF (2015) Potential of hydrogel-forming and dissolving microneedles for use in paediatric populations. Int J Pharm 489:158-169

Chen Y, Chen BZ, Wang QL, Jin X, Guo XD (2017) Fabrication of coated polymer microneedles for transdermal drug delivery. $\mathrm{J}$ Control Release 265:14-21

Chen S, Miyazaki T, Itoh M, Matsumoto H, Morooka Y, Tanaka M, Miyahara Y, Suganami T, Matsumoto A (2020) Temperature-stable boronate gel based microneedle technology for self-regulated insulin delivery. ACS Appl Polym Mater 7:2781-2790

Choi HJ, Bondy BJ, Yoo DG, Compans RW, Kang SM, Prausnitz MR (2012) Stability of whole inactivated influenza virus vaccine during coating onto metal microneedles. J Control Release 166:159-171

Choi IJ, Kang A, Ahn MH, Jun H, Baek S-K, Park J-H, Na W, Choi S-O (2018) Insertion-responsive microneedles for rapid intradermal delivery of canine influenza vaccine. J Control Release 286:460-466

Chu LY, Prausnitz MR (2011) Separable arrowhead microneedles. J Control Release 149:242-249

Courtenay AJ, McAlister E, McCrudden MTC, Vora L, Steiner L, Levin G, Levy-Nissenbaum E, Shterman N, Kearney M-C, McCarthy HO, Donnelly RF (2020) Hydrogel-forming microneedle arrays as a therapeutic option for transdermal esketamine delivery. J Control Release 322:177-186

Dardano P, Caliò A, Di Palma V, Bevilacqua MF, Di Matteo A, De Stefano L (2015) A photolithographic approach to polymeric microneedles array fabrication. Materials 8:8661-8673

Dharadhar S, Majumdar A, Dhoble S, Patravale V (2019) Microneedles for transdermal drug delivery: a systematic review. Drug Dev Ind Pharm 45:188-201
Donnelly RF, Singh TR, Tunney MM, Morrow DI, McCarron PA, O'Mahony C, Woolfson AD (2009) Microneedle arrays allow lower microbial penetration than hypodermic needles in vitro. Pharm Res 26:2513-2522

Donnelly RF, Singh TRR, Woolfson AD (2010) Microneedle-based drug delivery systems: microfabrication, drug delivery, and safety. Drug Deliv 17:187-207

Du H, Liu P, Zhu J, Lan J, Li Y, Zhang L, Zhu J, Tao J (2019) Hyaluronic acid-based dissolving microneedle patch loaded with methotrexate for improved treatment of psoriasis. ACS Appl Mater Interfaces 11:43588-43598

Economidou SN, Lamprou DA, Douroumis M (2018) 3D printing applications for transdermal drug delivery. Int J Pharm 544:415-424

Edens C, Collins ML, Goodson JL, Rota PA, Prausnitz MR (2015) A microneedle patch containing measles vaccine is immunogenic in non-human primates. Vaccine 33:4712-4718

Fernando GJP, Hickling J, Jayashi Flores CM, Griffin P, Anderson CD, Skinner SR, Davies C, Witham K, Pryor M, Bodle J, Rockman S, Frazer IH, Forster AH (2018) Safety, tolerability, acceptability and immunogenicity of an influenza vaccine delivered to human skin by a novel high-density microprojection array patch (Nanopatch). Vaccine 36:3779-3788

Gill HS, Prausnitz MR (2007a) Coated microneedles for transdermal delivery. J Control Release 117:227-237

Gill HS, Prausnitz MR (2007b) Coating Formulations for Microneedles. Pharm Res 24:1369-1380

Griffin P, Elliott S, Krauer K, Davies C, Rachel Skinner S, Anderson CD, Forster A (2017) Safety, acceptability and tolerability of uncoated and excipient-coated high density silicon micro-projection array patches in human subjects. Vaccine 35:6676-6684

Gupta J, Gill HS, Andrews SN, Prausnitz MR (2011) Kinetics of skin resealing after insertion of microneedles in human subjects. $\mathbf{J}$ Control Release 154:148-155

Haj-Ahmad R, Khan H, Arshad MS, Rasekh M, Hussain A, Walsh S, Li X, Chang MW, Ahmad Z (2015) Microneedle coating techniques for transdermal drug delivery. Pharmaceutics 7:486-502

Han D, Morde RS, Mariani S, La Mattina AA, Vignali E, Yang C, Barillaro G, Lee H (2020) 4D Printing of a bioinspired microneedle array with backward-facing barbs for enhanced tissue adhesion. Adv Funct Mater 30:1909197

He R, Niu Y, Li Z, Li A, Yang H, Xu F, Li F (2020) A Hydrogel Microneedle Patch for Point-of-Care Testing Based on Skin Interstitial Fluid. Adv Healthcare Mater 9:1901201

Henry S, McAllister DV, Allen MG, Prausnitz MR (1998) Microfabricated microneedles: a novel approach to transdermal drug delivery. J Pharm Sci 87:922-925

Hirobe S, Azukizawa H, Hanafusa T, Matsuo K, Quan YS, Kamiyama F, Katayama I, Okada N, Nakagawa S (2015) Clinical study and stability assessment of a novel transcutaneous influenza vaccination using a dissolving microneedle patch. Biomaterials 57:50-58

Hoang MT, Ita KB, Bair DA (2015) Solid microneedles for transdermal delivery of amantadine hydrochloride and pramipexole dihydrochloride. Pharmaceutics 7:379-396

Homayun B, Lin X, Choi HJ (2019) Challenges and recent progress in oral drug delivery systems for biopharmaceuticals. Pharmaceutics 11:129

Indermun S, Luttge R, Choonara YE, Kumar P, du Toit LC, Modi G, Pillay V (2014) Current advances in the fabrication of microneedles for transdermal delivery. J Control Release 185:130-138

Iriarte C, Awosika O, Rengifo-Pardo M, Ehrlich A (2017) Review of applications of microneedling in dermatology. Clin Cosmet Investig Dermatol 10:289-298 
Ita K (2018) Ceramic microneedles and hollow microneedles for transdermal drug delivery: Two decades of research. J Drug Deliv Sci Tec 44:314-322

Jiang J, Gill HS, Ghate D, McCarey BE, Patel SR, Edelhauser HF, Prausnitz MR (2007) Coated microneedles for drug delivery to the eye. Invest Ophthalmol Vis Sci 48:4038-4043

Johnson AR, Procopio AT (2019) Low cost additive manufacturing of microneedle masters. The 3D Print Med 5(1): 2-10

Johnson AR, Caudill CL, Tumbleston JR, Bloomquist CJ, Moga KA, Ermoshkin A, Shirvanyants D, Mecham SJ, Luft JC, DeSimone JM (2016) Single-step fabrication of computationally designed microneedles by continuous liquid interface production. PLoS ONE 11:e0162518

Jun H, Ahn M-H, Choi I-J, Baek S-K, Park J-H, Choi S-O (2018) Immediate separation of microneedle tips from base array during skin insertion for instantaneous drug delivery. RSC Adv 8:17786-17796

Kang G, Kim S, Yang H, Jang M, Chiang L, Baek JH, Ryu JH, Choi GW, Jung H (2019) Combinatorial application of dissolving microneedle patch and cream for improvement of skin wrinkles, dermal density, elasticity, and hydration. J Cosmet Dermatol 18:1083-1091

Kearney MC, McKenna PE, Quinn HL, Courtenay AJ, Larrañeta E, Donnelly RF (2019) Design and development of liquid drug reservoirs for microneedle delivery of poorly soluble drug molecules. Pharmaceutics 11:605

Kim YC, Park JH, Prausnitz MR (2012) Microneedles for drug and vaccine delivery. Adv Drug Deliv Rev 64:1547-1568

Kim JY, Han MR, Kim YH, Shin SW, Nam SY, Park JH (2016) Tiploaded dissolving microneedles for transdermal delivery of donepezil hydrochloride for treatment of Alzheimer's disease. Eur J Pharm Biopharm 105:148-155

Krieger KJ, Bertollo N, Dangol M, Sheridan JT, Lowery MM, O'Cearbhaill ED (2019) Simple and customizable method for fabrication of high-aspect ratio microneedle molds using lowcost 3D printing. Microsyst Nanoeng 5:42

Lahiji SF, Jang Y, Ma Y, Dangol M, Yang H, Jang M, Jung H (2018) Effects of dissolving microneedle fabrication parameters on the activity of encapsulated lysozyme. Eur J Pharm Sci 117:290-296

Lee JH, Jung YS, Kim GM, Bae JM (2018) A hyaluronic acid-based microneedle patch to treat psoriatic plaques: a pilot open trial. Br J Dermatol 178:e24-e25

Li W, Terry RN, Tang J, Feng MR, Schwendeman SP, Prausnitz MR (2019a) Rapidly separable microneedle patch for the sustained release of a contraceptive. Nat Biomed Eng 3:220-229

Li W, Tang J, Terry RN, Li S, Brunie A, Callahan RL, Noel RK, Rodriguez CA, Schwendeman SP, Prausnitz MR (2019b) Long-acting reversible contraception by effervescent microneedle patch. Science Adv 5:1-12

Li Y, Zhang H, Yang R, Laffitte Y, Schmill U, Hu W, Kaddoura M, Blondeel EJM, Cui B (2019c) Fabrication of sharp silicon hollow microneedles by deep-reactive ion etching towards minimally invasive diagnostics. Microsyst Nanoeng 5:41

Littauer EQ, Mills LK, Brock N, Esser ES, Romanyuk A, PulitPenaloza JA, Vassilieva EV, Beaver JT, Antao O, Krammer F, Compans RW, Prausnitz MR, Skountzou I (2018) Stable incorporation of GM-CSF into dissolvable microneedle patch improves skin vaccination against influenza. J Control Release 276:1-16

Lu Y, Mantha SN, Crowder CC, Chinchilla S, Shah KN, Yun YH, Wicker RB, Choi J-W (2015) Microstereolithography and characterization of poly(propylene fumarate)-based drug-loaded microneedle arrays. Biofabrication 7:045001

Lutton REM, Larrañeta E, Kearney M-C, Boyd P, Woolfson AD, Donnelly RF (2015) A novel scalable manufacturing process for the production of hydrogel-forming microneedle arrays. Int J Pharm 494:417-429
Luzuriaga MA, Berry DR, Reagan JC, Smaldone RA, Gassensmith JJ (2018) Biodegradable 3D printed polymer microneedles for transdermal drug delivery. Lab Chip 18:1223-1230

Ma G, Wu C (2017) Microneedle, bio-microneedle and bio-inspired microneedle: A review. J Control Release 251:11-23

Martanto W, Davis SP, Holiday NR, Wang J, Gill HS, Prausnitz MR (2004) Transdermal delivery of insulin using microneedles in vivo. Pharm Res 21:947-952

Martanto W, Moore JS, Kashlan O, Kamath R, Wang PM, O’Neal JM, Prausnitz MR (2006) Microinfusion using hollow microneedles. Pharm Res 23:104-113

McAllister DV, Wang PM, Davis SP, Park JH, Canatella PJ, Allen MG, Prausnitz MR (2003) Microfabricated needles for transdermal delivery of macromolecules and nanoparticles: fabrication methods and transport studies. PNAS 100:13755-13760

McCarthy PT, Otto KJ, Rao MP (2011) Robust penetrating microelectrodes for neural interfaces realized by titanium micromachining. Biomed Microdevices 13:503-515

McGrath MG, Vrdoljak A, O’Mahony C, Oliveira JC, Moore AC, Crean AM (2011) Determination of parameters for successful spray coating of silicon microneedle arrays. Int J Pharm 415:140-149

Melchels FP, Feijen J, Grijpma DW (2010) A review on stereolithography and its applications in biomedical engineering. Biomaterials 31:6121-6130

Migdadi EM, Courtenay AJ, Tekko IA, McCrudden MT, Kearney MC, McAlister E, McCarthy HO, Donnelly RF (2018) Hydrogel-forming microneedles enhance transdermal delivery of metformin hydrochloride. J Control Release 285:142-151

Mistilis MJ, Bommarius AS, Prausnitz MR (2015) Development of a thermostable microneedle patch for influenza vaccination. $\mathrm{J}$ Pharm Sci 104:740-749

Nejad H, Sadeqi A, Kiaee G, Sonkusale S (2018) Low-cost and cleanroom-free fabrication of microneedles. Microsyst Nanoeng $4: 17073$

Nguyen TT, Choi JA, Kim JS, Park H, Yang E, Lee WJ, Baek SK, Song M, Park JH (2019) Skin immunization with third-generation hepatitis B surface antigen using microneedles. Vaccine 37:5954-5961

Ogundele M, Okafor HK (2017) Transdermal drug delivery: Microneedles, their fabrication and current trends in delivery methods. J Pharm Res Int 18:1-14

Ono A, Azukizawa H, Ito S, Nakamura Y, Asada H, Quan YS, Kamiyama F, Katayama I, Hirobe S, Okada N (2017) Development of novel double-decker microneedle patches for transcutaneous vaccine delivery. Int J Pharm 532:374-383

Park S-H, Yang D-Y, Lee K-S (2009) Two-photon stereolithography for realizing ultraprecise three-dimensional nano/microdevices. Laser Photonics Rev 3:1-11

Park J-H, Choi S-O, Seo S, Choy YB, Prausnitz MR (2010) A microneedle roller for transdermal drug delivery. Eur J Pharma Biopharma 76:282-289

Park BJ, Choi HJ, Moon SJ, Kim SJ, Bajracharya R, Min JY, Han H-K (2019) Pharmaceutical applications of 3D printing technology: current understanding and future perspectives. Int J Pharm Investig 49:575-585

Perez Cuevas MB, Kodani M, Choi Y, Joyce J, O’Connor SM, Kamili S, Prausnitz MR (2018) Hepatitis B vaccination using a dissolvable microneedle patch is immunogenic in mice and rhesus macaques. Bioeng Transl Med 3:186-196

Petukhova TA, Hassoun LA, Foolad N, Barath M, Sivamani RK (2017) Effect of Expedited Microneedle-Assisted Photodynamic Therapy for Field Treatment of Actinic Keratoses: A Randomized Clinical Trial. JAMA Dermatol 153:637-643 
Prausnitz MR (2017) Engineering microneedle patches for vaccination and drug delivery to skin. Annu Rev Chem Biomol Eng 8:177-200

Prausnitz M, Langer R (2008) Transdermal drug delivery. Nat Biotechnol 26:1261-1268

Queiroz MLB, Shanmugam S, Santos LNS, Campos CA, Santos AM, Batista MS, Araújo AAS, Serafini MR (2020) Microneedles as an alternative technology for transdermal drug delivery systems: a patent review. Expert Opin Ther Pat 30:433-452

Quinn HL, Bonham L, Hughes CM, Donnelly RF (2015) Design of a dissolving microneedle platform for transdermal delivery of a fixed-dose combination of cardiovascular drugs. J Pharm Sci 104:3490-3500

Raphael AP, Crichton ML, Falconer RJ, Meliga S, Chen X, Fernando GJ, Huang H, Kendall MA (2016) Formulations for microprojection/microneedle vaccine delivery: structure, strength and release profiles. J Control Release 225:40-52

Rouphael NG, Paine M, Mosley R, Henry S, McAllister DV, Kalluri H, Pewin W, Frew PM, Yu T, Thornburg NJ, Kabbani S, Lai L, Vassilieva EV, Skountzou I, Compans RW, Mulligan MJ, Prausnitz MR, TIV-MNP 2015 Study Group (2017) The safety, immunogenicity, and acceptability of inactivated influenza vaccine delivered by microneedle patch (TIV-MNP 2015): a randomised, partly blinded, placebo-controlled, phase 1 trial. Lancet 390:649-658

Ryu HR, Jeong HR, Seon-Woo HS, Kim JS, Lee SK, Kim HJ, Baek JO, Park JH, Roh JY (2018) Efficacy of a bleomycin microneedle patch for the treatment of warts. Drug Deliv Transl Res $8: 273-280$

Schmidleithner C, Kalaskar DM (2018) Stereolithography. IntechOpen $1-22$

Serbin J, Egbert A, Ostendorf A, Chichkov BN, Houbertz R, Domann G, Schulz J, Cronauer C, Fröhlich L, Popall M (2003) Femtosecond laser-induced two-photon polymerization of inorganicorganic hybrid materials for applications in photonics. Opt Lett 200238:301-303

Shakya AK, Ingrole RSJ, Joshi G, Uddin MJ, Anvari S, Davis CM, Gill HS (2019) Microneedles coated with peanut allergen enable desensitization of peanut sensitized mice. J Control Release 314:38-47

Skoog SA, Miller PR, Boehm RD, Sumant AV, Polsky R, Narayan RJ (2015) Nitrogen-incorporated ultrananocrystalline diamond microneedle arrays for electrochemical biosensing. Diam Relat Mater 54:39-46

Spierings EL, Brandes JL, Kudrow DB, Weintraub J, Schmidt PC, Kellerman DJ, Tepper SJ (2018) Randomized, double-blind, placebo-controlled, parallel-group, multi-center study of the safety and efficacy of ADAM zolmitriptan for the acute treatment of migraine. Cephalalgia 38:215-224

Sullivan S, Koutsonanos D, del Pilar MM, Lee JW, Zarnitsyn V, Choi SO, Murthy N, Compans RW, Skountzou I, Prausnitz MR (2010) Dissolving polymer microneedle patches for influenza vaccination. Nat Med 16:915-920
Takada K, Sun H-B, Kawata S (2005) Improved spatial resolution and surface roughness in photopolymerization-based laser nanowriting. Appl Phys Lett 86:71122

Tan CWX, Tan WD, Srivastava R, Yow AP, Wong DWK, Tey HL (2019) Dissolving triamcinolone-embedded microneedles for the treatment of keloids: A single-blinded intra-individual controlled clinical trial. Dermatol Ther (Heidelb) 9:601-611

Tang J, Wang J, Huang K, Ye Y, Su T, Qiao L, Hensley MT, Caranasos TG, Zhang J, Gu Z, Cheng K (2018) Cardiac cell-integrated microneedle patch for treating myocardial infarction. Sci Adv 4(11):9365

Tas C, Joyce JC, Nguyen HX et al (2017) Dihydroergotamine mesylateloaded dissolving microneedle patch made of polyvinylpyrrolidone for management of acute migraine therapy. J Control Release 268:159-165

Tibbitt MW, Dahlman JE, Langer R (2016) Emerging frontiers in drug delivery. J Am Chem Soc 138:704-717

Waghule T, Singhvi G, Dubey SK, Pandey MM, Gupta G, Singh M, Dua K (2019) Microneedles: a smart approach and increasing potential for transdermal drug delivery system. Biomed Pharmacother 109:1249-1258

Wilke N, Mulcahy A, Ye S-R, Morrissey A (2005) Process optimization and characterization of silicon microneedles fabricated by wet etch technology. Microelectron J 36:650-656

Xu J, Xu B, Tao J, Yang Y, Hu Y, Huang Y (2017) Microneedleassisted, DC-targeted Codelivery of pTRP-2 and adjuvant of paclitaxel for transcutaneous immunotherapy. Small 13:1700666

Yang H, Kim S, Jang M, Kim H, Lee S, Kim Y, Eom YA, Kang G, Chiang L, Baek JH, Ryu JH, Lee YE, Koh J, Jung H (2019) Twophase delivery using a horse oil and adenosine-loaded dissolving microneedle patch for skin barrier restoration, moisturization, and wrinkle improvement. J Cosmet Dermatol 18:936-943

Ye Y, Yu J, Wen D, Kahkoska AR, Gu Z (2018) Polymeric microneedles for transdermal protein delivery. Adv Drug Deliv Rev 127:106-118

Yu J, Zhang Y, Ye Y, DiSanto R, Sun W, Ranson D, Ligler FS, Buse JB, Gu Z (2015) Microneedle-array patches loaded with hypoxiasensitive vesicles provide fast glucose-responsive insulin delivery. Proc Natl Acad Sci USA 112:8260-8265

Zheng Z, Diaz-Arévalo D, Guan H, Zeng M (2018) Noninvasive vaccination against infectious diseases. Hum Vaccin Immunother 14:1717-1733

Zhu DD, Zhang XP, Yu HL, Liu RX, Shen CB, Zhang WF, Cui Y, Guo XD (2019) Kinetic stability studies of HBV vaccine in a microneedle patch. Int J Pharm 567:118489

Publisher's Note Springer Nature remains neutral with regard to jurisdictional claims in published maps and institutional affiliations. 